\title{
Stage-specific survival and recurrence in patients with cutaneous malignant melanoma in Europe - a systematic review of the literature
}

This article was published in the following Dove Press journal:

Clinical Epidemiology

26 May 2016

Number of times this article has been viewed

\author{
Fernanda Costa Svedman' \\ Demetris Pillas ${ }^{2}$ \\ Aliki Taylor ${ }^{2}$ \\ Moninder Kaur ${ }^{2}$ \\ Ragnar Linder ${ }^{3}$ \\ Johan Hansson' \\ 'Department of Oncology-Pathology, \\ Karolinska Institutet, Karolinska \\ University Hospital Solna, Stockholm, \\ Sweden; ${ }^{2}$ Centre for Observational \\ Research, Amgen Ltd, Uxbridge, UK; \\ 3IMS Health Sweden, Stockholm, \\ Sweden
}

Background: Given the increasing incidence in cutaneous malignant melanoma (CMM) and the recent changes in the treatment landscape, it is important to understand stage-specific overall and recurrence-free survival patterns in Europe. Despite publications such as EUROCARE-5, there is limited information on stage-specific survival for CMM in Europe.

Method: We carried out a systematic literature review to provide an up-to-date summary of stage-specific survival and recurrence-free survival patterns in patients with CMM in Europe. Studies were included if they were published in Medline during the past 12 years and included information on stage-specific survival and/or recurrence in CMM.

Results: Of the 8,749 studies identified, 26 studies were included, representing nine countries. Collectively, the studies covered a population of 152,422 patients and included data from 1978 to 2011. Randomized clinical trials and single-center observational studies comprised the most common study designs, including five large registry-based studies. Stage-specific information for survival and recurrence varied: 5-year overall survival: 95\%-100\% (stage I), 65\%-92.8\% (stage II), 41\%-71\% (stage III), and 9\%-28\% (stage IV); 5-year relapse-free survival was reported less frequently: $56 \%$ (stage II), and 28\%-44\% (stage III). Studies reporting survival by sentinel node (SN) status reported 5-year overall survival as 80\%-95\% for negative SN (stage I/II) and $35 \%-75 \%$ for positive SN (stage III) status; recurrence-free survival at 5 years: $76 \%-90 \%$ for negative and 35\%-58\% for positive SN status. Some studies included comparisons of survival by key patient sociodemographic characteristics, suggesting that these have a substantial influence on survival and recurrence estimates.

Conclusion: The studies identified in this review show large variations in stage-specific overall and recurrence-free survival by study type and by country. Owing to differing study designs and populations, it is difficult to make detailed comparisons. Large population-based studies that include stage-specific survival and recurrence in Europe are therefore important.

Keywords: cutaneous malignant melanoma, cancer, survival, recurrence, Europe, stage

\section{Introduction}

Cutaneous malignant melanoma (CMM) is the ninth most common cancer in Europe, with an annual incidence of 13.5 new cases per 100,000 population and over 100,000 new cases diagnosed in 2012 (3\% of total cancers). ${ }^{1}$

With a steady increasing trend in annual incidence rates, ${ }^{2}$ the incidence of CMM is increasing more rapidly than that of any other cancer in Europe - apart from lung cancer in women. ${ }^{3}$ Large differences in CMM incidence and mortality exist between European countries, with the highest estimated age-standardized incidence of CMM reported in Switzerland for men and in Denmark for women. Central and Eastern
Correspondence: Fernanda Costa Svedman Department of Oncology-Pathology, Karolinska Institutet, Karolinska University Hospital Solna, Stockholm I7I 76, Sweden

$\mathrm{Tel}+46735109134$

Fax + $4685 \quad 1774323$

Email fernanda.costa-svedman@ karolinska.se
Clinical Epidemiology 2016:8 109-122

Dovepress

http://dx.doi.org/10.2147/CLEP.S99021 (c) (i) (5) 2016 Svedman et al. This work is published and licensed by Dove Medical Press Limited. The full terms of this license are available at https://www.dovepress.com/terms. cC) you hereby accept the Terms. Non-commercial uses of the work are permitted without any further permission from Dove Medical Press Limited, provided the work is properly attributed. For permission for commercial use of this work, please see paragraphs 4.2 and 5 of our Terms (https://www.dovepress.com/terms.php). 
European countries have the lowest reported incidence rates in Europe. A total of 22,211 deaths due to CMM were estimated in Europe in 2012, with annual CMM mortality rates per 100,000 population ranging between 0.5 (Albania) and 3.6 (Norway). ${ }^{1}$ It has been suggested that some of the differences in CMM incidence and mortality may be due to missed opportunities for early diagnosis and incomplete reporting of $\mathrm{CMM}^{4}$

In cancer, early detection alone may not necessarily lead to good survival rates; however, CMM is an example in which early detection is associated with higher cure rates. ${ }^{5}$ There is known variation in reported 5-year survival by country and region in Europe. EUROCARE- $5^{6}$ analyzed data from more than 10 million patients with cancer diagnosed up to 2007 with follow-up until 2008. Five-year relative survival for CMM was $83.2 \%$, which has not improved since EUROCARE-4. ${ }^{7,8}$ EUROCARE-5 reports variation in 5 -year relative survival by region, with best survival rates in northern and central Europe ( $87.7 \%$ and $87.6 \%$, respectively) compared to $82.6 \%$ in southern Europe and $74.3 \%$ in Eastern Europe. This variation may be due to later stage at diagnosis and differences in treatment regimes. ${ }^{6,9}$

Despite attempts to collect and consolidate information in various databases, there are limited published data on stage-specific survival in Europe. Although surgery remains the definitive treatment for patients with earlier-stage CMM (stage I-III), there has been an increase in the use of newly approved drugs for systemic treatment of patients with unresectable and stage IV disease. However, since these novel therapies were introduced relatively recently, it is unlikely that they have influenced survival rates presented in this study. Until recently, interferon $2 \alpha$ remained the only approved systemic adjuvant therapy for patients with stage IIB-III CMM and has minimal effect on patient overall survival (OS). Ipilimumab as adjuvant therapy has now been shown to improve progression-free survival (PFS) in patients with radically resected stage III CMM and is approved in the USA for this indication. ${ }^{10}$ Ipilimumab is a monoclonal antibody approved for first- and second-line treatment of advanced CMM since 2011; it typically achieves response rates of $5 \%-15 \%$ in patients with regional and distant metastases ${ }^{11}$ and is associated with long-term survival in approximately $20 \%$ of patients. ${ }^{12}$ In patients with BRAF V600E (or the rarer V600K) mutated stage IV CMM, the BRAF inhibitors vemurafenib and dabrafenib have demonstrated response rates of approximately $50 \% .{ }^{13}$ Encouragingly, treatment of advanced $\mathrm{CMM}$ continues to evolve, with new agents now targeting the programmed death ligand-receptor interaction, such as the
anti-PD1 antibodies pembrolizumab and nivolumab, and also targeted drugs that can be used in combination with BRAF inhibitors to inhibit the MAP-kinase pathway, such as the MEK inhibitors trametinib and cobimetinib. ${ }^{14,15}$

Given the increasing incidence of all-stages CMM and changes in the treatment landscape, it is important to understand the stage-specific survival and recurrence-free survival patterns in Europe from contemporary data and review the reported variation. Reporting stage-specific survival is of importance as the overall CMM survival data may be confounded by an increase over time in proportions of patients diagnosed with early-stage disease (stage I) and a change in staging because of implementation of sentinel node ( $\mathrm{SN}$ ) procedure. ${ }^{16}$

We carried out a systematic review with the objective to evaluate published robust data on stage-specific survival as well as recurrence-free survival by stage in patients with CMM in Europe.

\section{Materials and methods}

\section{Search strategy and study inclusion criteria}

We developed and followed a standard protocol for this review according to the PRISMA guidelines for systematic reviews, which define a rigorous process of study identification, screening, eligibility, and inclusion (Table S1). ${ }^{17}$ Studies were considered eligible for inclusion in this review if they were published during the past 12 years (period of publication from January 1, 2004 to December 31, 2015). All included studies were published in English. To ensure study quality, only those published in national or international peerreviewed journals were considered. Studies were considered for inclusion only if they reported stage-specific rates of survival and/or recurrence in adult ( $\geq 18$ years of age) patients with CMM. In order to include only studies with more robust outcome data with stage-specific information, studies with fewer than 400 patients were excluded. The cutoff of 400 patients per study was reached after initial review of studies, which showed that the quality of smaller studies was poorer and included mainly single-institution retrospective studies. With only a small proportion of patients in the advanced and metastatic setting in these publications, the accuracy of survival reported and follow-up time recorded in smaller studies was seen to be of poor quality and not relevant to this review paper. Also excluded were reviews, meta-analyses, and case reports.

Study identification and data extraction were performed by searching the Medline scientific literature database using the following search terms: "melanoma", "skin 
cancer", "survival", "mortality", "recurrence", "metastatic", "metastases" (full search terms provided in Table S2). In addition, relevant references and bibliographies were manually searched by trained researchers for additional studies. An initial review of titles and abstracts, and subsequently, a full review of all remaining search results were carried out independently by two reviewers to determine whether they met the criteria for inclusion in this review (Figure S1). All disagreements were resolved via review by a third reviewer.

\section{Data extraction and synthesis}

From each of the identified studies, the following information was extracted: author name(s), date of publication, date/period of coverage of study, study country/countries, description of study population, demographic information, follow-up duration, overall and stage-specific survival, and overall and stage-specific recurrence-free survival rate. Additional information of interest for the particular study was also noted, including potential sources of confounding and whether any sensitivity analyses were performed. In studies where rates were provided for various years, only the most recent estimates were included.

All extracted information was synthesized with the overall interpretation of the findings, taking into account potential sources of study heterogeneity, demographic background of CMM patients, follow-up duration, and potential sources of confounding.

\section{Results}

A total of 8,749 studies were identified from the Medline database search, of which 26 studies were included. The studies included populations from nine countries (Denmark, Finland, France, Germany, Italy, the Netherlands, Poland, Sweden, and the United Kingdom), with the majority of studies being from northern Europe (Table 1). ${ }^{18-43}$ Collectively, the identified studies covered a population of 152,422 European patients. We included 5 large population-based registry studies ${ }^{18-20,42,43}$ (Table 2), 7 randomized clinical trials (RCTs) $)^{21-27}$ (Table 3), and 14 observational studies ${ }^{28-41}$ (Table 4). The 26 identified studies collectively included data on CMM patients from 1978 to 2011. Overall, across countries and by study type, stagespecific information for survival and recurrence varied: 5-year OS: 95\%-100\% (stage I), 65\%-92.8\% (stage II), 41\%-71\% (stage III), and 9\%-28\% (stage IV); 5-year relapse-free survival (RFS) was reported less frequently: 56\% (stage II) and $28 \%-44 \%$ (stage III). Studies reporting survival by SN status reported 5-year OS as $80 \%-95 \%$ for negative $\mathrm{SN}$ (stage I/II) and 35\%-75\% for positive SN (stage III) status; recurrence-free survival at 5 years was $76 \%-90 \%$ for negative and $35 \%-58 \%$ for positive $\mathrm{SN}$ status.

Pooling the survival data from population registry studies, RCTs, and observational studies provides a wide variation in the survival and recurrence data. We have presented these data by study type in Tables 2-4.

Although the staging system used by studies included in this review was not always clearly stated, most studies used the staging system of the American Joint Committee on Cancer (AJCC) or the corresponding Union for International Cancer Control (UICC) staging system.

Five population registries with large patient cohorts were identified from Denmark, ${ }^{43}$ Germany, ${ }^{18}$ Sweden, ${ }^{19,42}$ and the Netherlands. ${ }^{20}$ The Danish study included 27,010 patients; the German study, 37,155 patients; the two Swedish studies, 5,915 and 27,235 patients; and the Dutch registry, 33,181 patients (Table 2). Although the primary purpose of the Dutch publication was to study outcomes from CMM of unknown primary origin, only $2.6 \%$ of patients $(n=857)$ fell into this category. No significant difference existed between the two groups of patients (CMM of known primary and unknown primary) reporting a 5-year survival of 55\% for

Table I Number of included studies by country and key study characteristics

\begin{tabular}{|c|c|c|c|c|}
\hline Country & $\begin{array}{l}\text { Number of } \\
\text { studies }\end{array}$ & $\begin{array}{l}\text { Number of patients } \\
\text { (range of patients) }\end{array}$ & $\begin{array}{l}\text { Number of patients } \\
\text { (across studies) }\end{array}$ & $\begin{array}{l}\text { Time-period covered } \\
\text { (range of years) }\end{array}$ \\
\hline Multi-country studies ${ }^{22-27}$ & 6 & $444-1,388$ & 5,709 & $1988-2004$ \\
\hline Italy ${ }^{33-37}$ & 5 & $\mathrm{I}, 108-2,954$ & 8,060 & 1980-2009 \\
\hline Germany ${ }^{18,30-32}$ & 4 & $697-37,155$ & 41,193 & 1978-2007 \\
\hline Poland 88,39 & 2 & 459-I,207 & 1,666 & 1994-2007 \\
\hline Sweden ${ }^{19,42}$ & 2 & $5,915-27,235$ & 33,150 & |990-20| | \\
\hline The Netherlands ${ }^{20,40}$ & 2 & $429-33,181$ & 33,610 & 1995-2009 \\
\hline$U_{K}^{21,4 I}$ & 2 & $472-674$ & $\mathrm{I}, 146$ & 1995-2003 \\
\hline Denmark $^{43}$ & I & 27,010 & 27,010 & $|989-20| \mid$ \\
\hline Finland ${ }^{28}$ & I & 423 & 423 & 2002-2009 \\
\hline France $^{29}$ & I & 455 & 455 & 1999-2004 \\
\hline Total & 26 & $423-37,155$ & 152,422 & |978-20| | \\
\hline
\end{tabular}


Table 2 Five-year stage-specific survival from five large population-based registry studies (Denmark, Germany, Sweden, and the Netherlands)

\begin{tabular}{|c|c|c|c|c|c|c|}
\hline Country & Study & Registry coverage & Study period & $\begin{array}{l}\text { Population } \\
\text { (N and stage) }\end{array}$ & $\begin{array}{l}\text { Survival analysis } \\
\text { type }\end{array}$ & 5-year survival \\
\hline Denmark & Bay et $\mathrm{al}^{43}$ & National coverage & |989-20| | & $\begin{array}{l}27,010 \text { patients } \\
\text { (all stages) }\end{array}$ & $\begin{array}{l}\text { Relative survival, } \\
\text { age-adjusted }\end{array}$ & $\begin{array}{l}\text { All stages: } 90 \% \text { (women) } \\
82 \% \text { (men) } \\
\text { Stage I: } 95 \%-98 \% \\
\text { Stage II: } 78 \%-89 \% \\
\text { Stage III: } 59 \%-71 \% \\
\text { Stage IV: } 13 \%-25 \%\end{array}$ \\
\hline Germany & $\begin{array}{l}\text { Eisemann } \\
\text { et } \mathrm{al}^{18}\end{array}$ & $\begin{array}{l}\text { I I cancer registries } \\
\text { (33 million people, } 40 \% \\
\text { of German population) }\end{array}$ & 1997-2006 & $\begin{array}{l}37,155 \text { patients } \\
\text { (all stages) }\end{array}$ & $\begin{array}{l}\text { Relative survival, } \\
\text { age-adjusted }\end{array}$ & $\begin{array}{l}\text { All stages: }{ }^{\text {d } 91.9 \%} \text { (women) } \\
87.0 \% \text { (men) } \\
\text { Stage IV ( } n=I, I \mid 7): 18.2 \%- \\
28.2 \%^{a}\end{array}$ \\
\hline Sweden & $\begin{array}{l}\text { Eriksson } \\
\text { et } \text { al }^{19}\end{array}$ & National coverage & 1990-2007 & $\begin{array}{l}27,235 \text { patients } \\
\text { (all stages); } \\
609 \text { stage III } \\
\text { and I } 96 \text { stage IV }\end{array}$ & $\begin{array}{l}\text { Crude disease-specific } \\
\text { survival (Kaplan-Meier) }\end{array}$ & $\begin{array}{l}\text { Stage I: } 97.3 \%(97.0 \%-97.5 \%)^{\mathrm{b}} \\
\text { Stage II: } 72.5 \%(71.2 \%-73.8 \%) \\
\text { Stage III: } 41.3 \%(37.0 \%-45.5 \%) \\
\text { Stage IV: I7.8\% (I2.3\%-24.I\%) }\end{array}$ \\
\hline Sweden & $\begin{array}{l}\text { Plym } \\
\text { et } \mathrm{al}^{42}\end{array}$ & $\begin{array}{l}\text { Uppsala/Örebro region } \\
\text { (2 million people, } 21 \% \\
\text { of Swedish population) }\end{array}$ & |997-20| | & $\begin{array}{l}5,915 \text { patients } \\
\text { (all stages) }\end{array}$ & $\begin{array}{l}\text { Relative survival, } \\
\text { age-adjusted }\end{array}$ & $\begin{array}{l}\text { Stage I: } 97.7 \%-100 \% \\
\text { Stage II: } 69.0 \%-92.8 \% \\
\text { Stage III: } 44.7 \%-59.0 \%\end{array}$ \\
\hline The Netherlands & $\begin{array}{l}\text { de Waal } \\
\text { et } \mathrm{al}^{20}\end{array}$ & National coverage & 2003-2009 & $\begin{array}{l}33,18 \mathrm{I} \text { patients } \\
\text { (all stages), } \\
\text { (I,689 stage III } \\
\text { and } 286 \text { stage IV) }\end{array}$ & $\begin{array}{l}\text { Crude all-cause survival } \\
\text { (Kaplan-Meier) }\end{array}$ & $\begin{array}{l}\text { Stage III: } 54.6 \%(51.3 \%-57.9 \%)^{c} \\
\text { Stage IV: } 8.9 \%(4.5 \%-13.3 \%)\end{array}$ \\
\hline
\end{tabular}

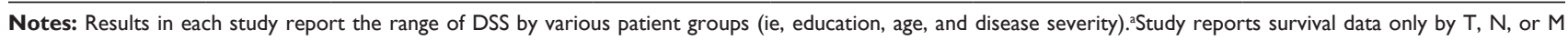
classification, making a precise estimate for stages I, II, and III impossible since a low T stage can be node-positive (and thus stage III). The exception for this is MI disease (stage IV). b Lyth, Regional Cancer Center, Linköping, Sweden, personal communication, March, 20I5. 'Data is merged from patients with melanoma of unknown primary and melanoma with known primary origin. Five-year survival $(95 \% \mathrm{Cl})$ for stage III with macroscopic disease, one lymph node involved was $50.1 \%$ ( $43 \%-57.3 \%$ ), for stage III macroscopic disease and more than one positive lymph node was $27.1 \%$ (20.7\%-33.5\%). Five-year survival ( $95 \% \mathrm{Cl})$ for stage IV, subcutaneous or distant lymph nodes was $35.3 \%(17.5 \%-53 \%)$, for stage IV, with lung metastasis was $5.4 \%(0 \%-15.3 \%)$, and for stage IV with metastasis to other distant sites was $1.5 \%(1.2 \%-4.1 \%)$. ${ }^{d}$ Overall stagespecific results are not provided, only for each separate age, sex, and socioeconomic deprivation group.

Abbreviations: $\mathrm{Cl}$, confidence interval; DSS, disease-specific survival.

stage III and $9 \%$ for stage IV. ${ }^{20}$ The first Swedish study is a comprehensive nationwide study of the survival pattern of CMM. The primary purpose of this study was to report the association of level of education with stage at diagnosis and survival in CMM, and this study reported poorer survival in those with lower level of education. ${ }^{19}$ For this review, we obtained results from study authors (J Lyth, Regional Cancer Center, Linköping, Sweden, personal communication, March, 2015), with 5-year survival reported as $41.3 \%$ (95\% confidence interval $37.0 \%-45.5 \%$ ) for stage III disease and $17.8 \%(12.3 \%-24.1 \%)$ for stage IV disease. The second Swedish study extracts information from an extensive population-based register covering a population of 2 million people. The main objective of this study was to compare the epidemiological data, management, and outcome of CMM between the younger and the older patient population. Results presented show a significant difference between these two groups of patients regarding all the aspects mentioned earlier, with younger patients having better survival rates. ${ }^{42}$ The German registry study of CMM covers $40 \%$ of the total
German population. Results are reported as age-adjusted relative survival by TNM classification, and we estimated the stage IV age-adjusted relative survival to be $18 \%-28 \%$ at 5 years. ${ }^{18}$ Finally, the Danish population-based register study included 27,010 CMM patients diagnosed between 1989 and 2011 with the aim to investigate the trends in incidence and in survival of CMM in Denmark. The study found that the incidence of CMM in Denmark had more than doubled over the 23-year study period, with the increase seen mainly in lower stage groups and superficial spreading CMM. Agestandardized relative OS had increased in recent years for both men and women. ${ }^{43}$

We included seven RCTs (Table 3) that reported survival using Kaplan-Meier methodology and recurrence rates from 4 to 8 years. Six RCTs compared outcomes in patients with CMM with stage IIB-III or stage III disease using interferon alfa $2 \mathrm{a}$ or $2 \mathrm{~b}$ as the investigational treatment $\mathrm{arm}$. The number of patients included ranged from $444^{24}$ to 1,388 patients. ${ }^{23}$ The results show some differences in long-term OS and some improvement in RFS in patients treated with interferon. . $^{23,24,26}$ 
Table 3 Stage-specific survival rate and recurrence-free survival rate in CMM patients from seven randomized controlled trials (at 5 years unless reported otherwise)

\begin{tabular}{|c|c|c|c|c|c|c|}
\hline Country & Study & Clinical trial design & $\begin{array}{l}\text { Study } \\
\text { period }\end{array}$ & $\begin{array}{l}\text { Population } \\
\text { (N and stage) }\end{array}$ & $\begin{array}{l}\text { Stage-specific overall } \\
\text { survival for both } \\
\text { treatment arms }\end{array}$ & $\begin{array}{l}\text { Stage-specific RFS in } \\
\text { both treatment arms }\end{array}$ \\
\hline UK & $\begin{array}{l}\text { Hancock } \\
\text { et } \mathrm{al}^{21}\end{array}$ & $\begin{array}{l}\text { Interferon alfa } 2 \text { a versus no } \\
\text { further treatment in radically } \\
\text { resected melanoma }\end{array}$ & $1995-2000$ & $\begin{array}{l}674 \text { patients } \\
\text { (stage IIB/III) }\end{array}$ & $\begin{array}{l}\text { Stage IIB/III: } 44 \% \\
\text { (both groups) }\end{array}$ & $\begin{array}{l}\text { Stage IIB/III: 32\% (both } \\
\text { groups) }\end{array}$ \\
\hline Multi-country & $\begin{array}{l}\text { Kleeberg } \\
\text { et } \mathrm{al}^{22}\end{array}$ & $\begin{array}{l}\text { Interferon } \alpha \text { versus interferon } \\
\gamma \text { versus mistletoe extract } \\
\text { versus observation after } \\
\text { surgery in patients with either } \\
\text { thickness }>3 \mathrm{~mm} \text { or regional } \\
\text { lymph node metastasis }\end{array}$ & $1988-1996$ & $\begin{array}{l}830 \text { patients } \\
\text { (stage IIB/III) }\end{array}$ & $\begin{array}{l}\text { Stage IIB: } 55 \%^{\mathrm{a}} \\
\text { approximately (all groups) } \\
\text { Stage III: } 35 \%^{\mathrm{a}} \\
\text { approximately (all groups) } \\
\text { Stage IIB and III: } 40 \% \text { at } \\
8 \text { years }\end{array}$ & $\begin{array}{l}\text { Stage IIB: } 39.3 \% \text { (all groups) } \\
\text { Stage III: } 27.6 \% \text { (all groups) } \\
\text { Stage IIB/III: } 32.4 \% \text { (RFS at } \\
8 \text { years) }\end{array}$ \\
\hline Multi-country & $\begin{array}{l}\text { Eggermont } \\
\text { et } \mathrm{al}^{23}\end{array}$ & $\begin{array}{l}\text { Intermediate doses of } \\
\text { interferon alfa } 2 b \text { versus } \\
\text { observation }\end{array}$ & $1996-2000$ & $\begin{array}{l}\text { I,388 patients } \\
\text { (stage IIB/III) }\end{array}$ & $\begin{array}{l}\text { All Stage IIB and III: } 50.2 \% \text {; } \\
47.7 \% \text { (observation); } 48.3 \% \\
\text { and } 53.1 \% \text { interferon groups } \\
\text { Stage IIB: } 66.0 \% \text { (all) } \\
\text { Stage III NI: } 55.5 \% \text { (all) } \\
\text { Stage III N2: } 39.4 \% \text { (all) at } \\
4.5 \text { years }\end{array}$ & $\begin{array}{l}\text { All Stage IIB and III: } 43.3 \% \text {; } \\
40 \% \text { (observation); } 42.3 \% \\
\text { and } 46.1 \% \text { (interferon } \\
\text { groups) } \\
\text { Stage IIB: } 59.5 \% \text { (all) } \\
\text { Stage III NI: } 51.4 \% \text { (all) } \\
\text { Stage III N2: } 31.0 \% \text { (all) }\end{array}$ \\
\hline Multi-country & $\begin{array}{l}\text { Garbe } \\
\text { et } \mathrm{al}^{24}\end{array}$ & $\begin{array}{l}\text { Interferon alfa 2a plus or } \\
\text { minus dacarbazine versus } \\
\text { surgery alone in patients } \\
\text { with regional lymph nodes } \\
\text { metastases }\end{array}$ & $|997-200|$ & $\begin{array}{l}444 \text { patients } \\
\text { (stage III) }\end{array}$ & $\begin{array}{l}\text { Stage III: } 42.4 \% \text { surgery; } \\
59 \% \text { (interferon) } 45.2 \% \\
\text { (interferon + dacarbazine) }^{c}\end{array}$ & $\begin{array}{l}\text { Stage III: } 27.3 \% \text { surgery; } \\
39 \% \text { (interferon); } 29.4 \% \\
\text { (interferon + dacarbazine) } \\
\text { (RFS at } 4 \text { years) }\end{array}$ \\
\hline Multi-country & $\begin{array}{l}\text { Eggermont } \\
\text { et } \mathrm{al}^{25}\end{array}$ & $\begin{array}{l}\text { Interferon alfa } 2 \mathrm{~b} \text { versus } \\
\text { observation in resected } \\
\text { stage III melanoma }\end{array}$ & $2000-2003$ & $\begin{array}{l}\text { I,256 patients } \\
\text { (stage III) }\end{array}$ & $\begin{array}{l}\text { Stage III: } 46.4 \% \\
\text { (observation) and } 47.8 \% \\
\text { (interferon); I positive } \\
\text { LN: } 6 I .4 \% \text { (observation) } \\
\text { and } 64.3 \% \text { (interferon); } \\
>\text { I positive LN: } 40.5 \% \\
\text { (observation) and } 48.5 \% \\
\text { (interferon) at } 7 \text { years }\end{array}$ & $\begin{array}{l}\text { Stage III } 34.6 \% \\
\text { (observation) and } 39.1 \% \\
\text { (interferon), } \\
\text { I positive LN: } 46.8 \% \\
\text { (observation) and } 52.3 \% \\
\text { (interferon); > I positive } \\
\text { LN: } 26.9 \% \text { (observation) } \\
\text { and } 35.5 \% \text { (interferon) } \\
\text { (RFS at } 7 \text { years) }\end{array}$ \\
\hline Multi-country & $\begin{array}{l}\text { Hansson } \\
\text { et } \mathrm{al}^{26}\end{array}$ & $\begin{array}{l}\text { Two different durations } \\
\text { of adjuvant therapy with } \\
\text { intermediate-dose interferon } \\
\text { alfa } 2 b \text { in patients with high- } \\
\text { risk melanoma }\end{array}$ & 1996-2004 & $\begin{array}{l}855 \text { patients } \\
\text { (stage IIB/IIC/III) }\end{array}$ & $\begin{array}{l}\text { Stage IIB/III: } 56.1 \text { months } \\
\text { median survival in control } \\
\text { group; } 72.1 \text { and } 64.3 \text { months } \\
\text { in treatment groups. Median } \\
\text { follow-up time } 72.4 \text { months }\end{array}$ & $\begin{array}{l}\text { Stage IIB/III: } 23.2 \text { months } \\
\text { median RFS; } 37.8 \text { and } \\
28.6 \text { months in treatment } \\
\text { arms }\end{array}$ \\
\hline Multi-country & $\begin{array}{l}\text { Gillgren } \\
\text { et } \mathrm{al}^{27}\end{array}$ & $\begin{array}{l}2 \mathrm{~cm} \text { versus } 4 \mathrm{~cm} \text { surgical } \\
\text { excision margins for primary } \\
\text { cutaneous melanoma thicker } \\
\text { than } 2 \mathrm{~mm}\end{array}$ & 1992-2004 & $\begin{array}{l}936 \text { patients } \\
\text { (stage II) }\end{array}$ & Stage II: $65 \%$ (both groups) & Stage II: $56 \%$ (both groups) \\
\hline
\end{tabular}

Notes: Survival reported is Kaplan-Meier overall survival. a Data were extracted from figures. ${ }^{\mathrm{b}}$ This study has reported distant metastases-free survival at 4.5 years, not RFS. 'This study has reported disease-specific survival at 4 years and not overall survival.

Abbreviations: CMM, cutaneous malignant melanoma; LN, lymph node; RFS, recurrence-free survival

Survival varied from approximately $35 \%-50 \%^{21,23-26}$ in control groups to approximately $50 \%-60 \%$ for those treated with interferon for stage IIB/III patients. ${ }^{23-26}$ The recurrence-/ RFS rate in stage IIB/III patients reported at 5 years was approximately $30 \%{ }^{21,22}$ overall; in stage III patients, the rate was approximately $30 \%-35 \%$ for those patients not treated with interferon, and was $40 \%-45 \%$ for those treated with interferon. ${ }^{24,25}$ As these studies report recurrence-free survival rates in different groups, further comparisons are difficult to make. Gillgren et $\mathrm{al}^{27}$ presented results comparing 2 versus $4 \mathrm{~cm}$ excision margins on survival for 936 patients with stage II CMM and reported OS to be $65 \%$ at 5 years, and stage-specific rate of recurrence to be $56 \%$.

Table 4 provides a summary of 14 observational studies: four retrospective and 10 prospective studies, including one from a CMM university registry ${ }^{31}$ that reported 13 years of follow-up. The range of median follow-up in the prospective studies was from 3 years $^{38}$ to more than 18 years $^{36}$. 


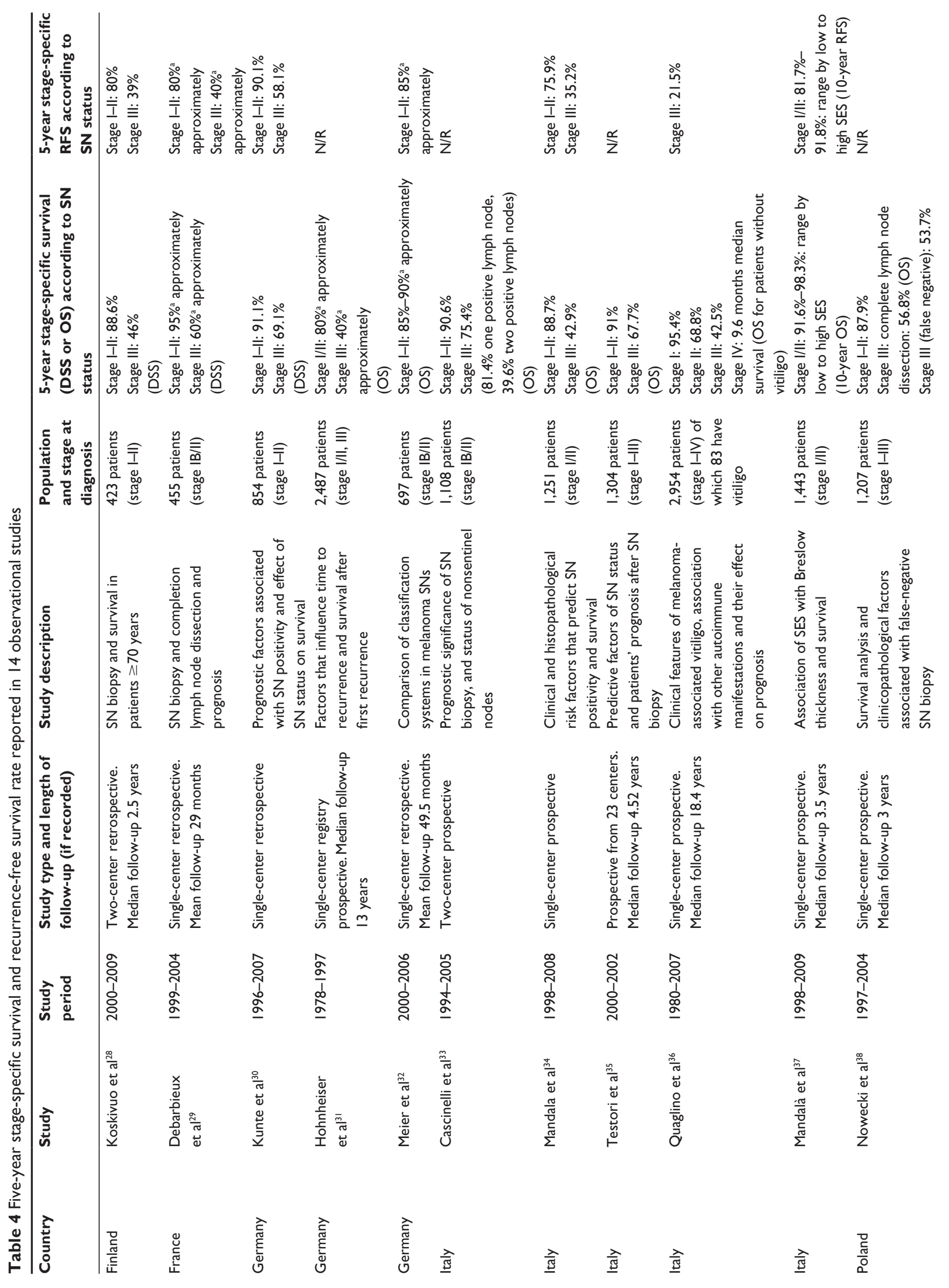



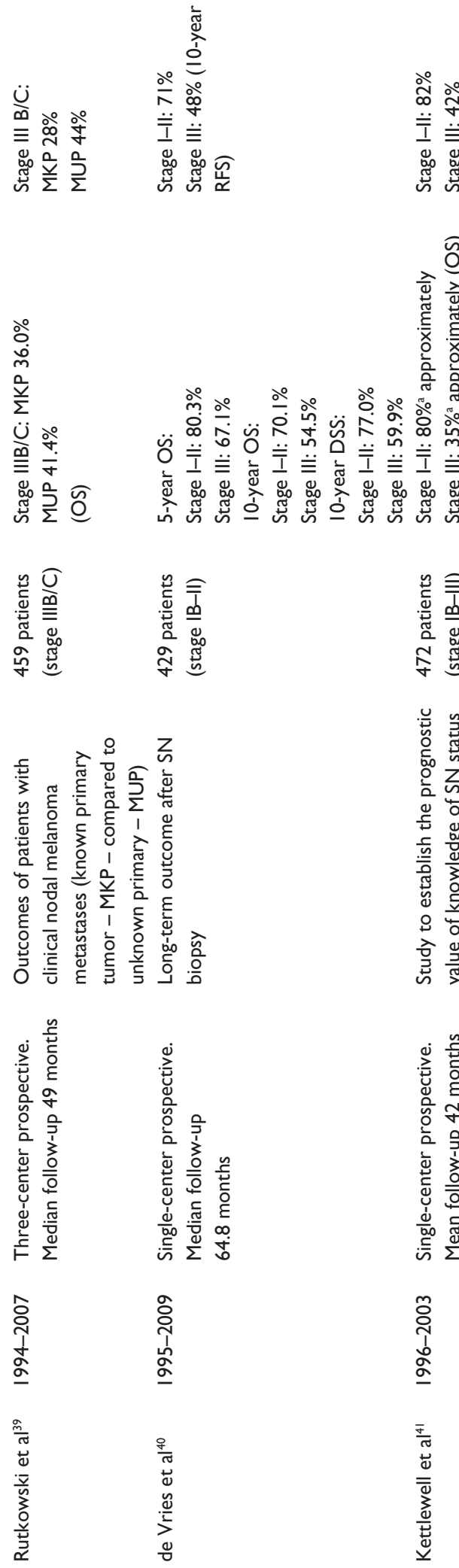

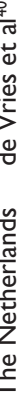

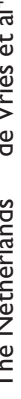

Ten studies were designed to study outcomes after SN biopsy in early-stage CMM, with follow-up to more advanced disease..$^{28-30,32-35,38,40,41}$ These studies do not report stage, rather they report the outcome of SN biopsy (negative or positive). It is possible to assume that a patient with a negative SN biopsy is stage I or II, while those with a positive SN are stage III (or possibly stage IV) CMM. Survival in SN-negative patients is consistently higher than that for SN-positive patients: range $80 \%-95 \%$ at 5 years compared to $35 \%-75 \%$, respectively. Recurrence-free survival rate at 5 years ranges from $76 \%$ to $90 \%$ in SN-negative patients and from $35 \%$ to $58 \%$ in SN-positive patients. Of the remaining four observational studies listed in Table 4, one study was designed to look at recurrence and survival in a large registry study, ${ }^{31}$ one studied CMM associated vitiligo, ${ }^{36}$ one studied the effect of socioeconomic status (SES) on survival, ${ }^{37}$ and the final study ${ }^{39}$ reported the outcomes in patients with unknown primary disease compared to those with known primary disease.

\section{Discussion}

To our knowledge, this is the first systematic review of stage-specific survival and recurrence of CMM patients in Europe. Our review identified a relatively small number of published studies $(n=26)$ with over 400 patients and stagespecific outcome data. These were predominantly based in Northern Europe, where considerably higher CMM incidence rates are reported, ${ }^{44}$ compared with southern Europe, and survival is known to be better. ${ }^{6}$ Apart from the differences in the incidence and survival between countries, there are also differences in screening, early detection, treatment, and follow-up. Straightforward between-country comparisons are complicated by the large differences observed in study design and patient inclusion criteria, treatments, patient numbers, measurements reported for survival and recurrence, and duration of follow-up. The data provided by the identified studies, when taken collectively, provide an informative general overview of the range and variability of CMM stage-specific treatment outcomes in Europe, as well as of the research gaps, which are evident in this area. Patients included in these studies were diagnosed between 1978 and 2011. The SN biopsy procedure, introduced in the 1990s, has likely led to stage migration in all European countries where it has been implemented. This may mean that some patients previously classified as stage I and II are now being categorized as stage III. This may have led to a perceived improvement in survival for stages I and II, because patients with microscopically positive lymph nodes 
and poorer prognosis are now correctly being classified as stage III. At the same time, the stage III group may now include patients with a relatively better prognosis (with microscopically positive lymph nodes), which may have led to an overall improved prognosis in stage III CMM (so-called Will Rogers phenomenon). ${ }^{16}$

Currently, 5-year relative survival after CMM in Europe is, overall, $83 \%$, with variation by country and region. ${ }^{6,9}$ Survival after a diagnosis of CMM varies widely by stage, and, in this review, we confirmed a large variability in survival. We included five large population-based registry studies from Denmark, Germany, Sweden, and the Netherlands: survival reported varied by study. ${ }^{18-20,42,43}$ The German, ${ }^{18}$ the Danish, ${ }^{43}$ and one of the Swedish studies ${ }^{42}$ reported relative survival; the Dutch study ${ }^{20}$ reported the crude all-cause survival; and the other Swedish study ${ }^{19}$ reported the crude disease-specific survival (DSS). Five-year survival in stage IV disease was the lowest in the Dutch study and was better in the Swedish (18\%) and German studies (18\%-28\%). The completeness of stage at primary diagnosis and mortality data in all five registries is thought to be comprehensive; however, it is not known how accurately recurrence is reported. The Swedish study ${ }^{19}$ linked several population-based nationwide registers and censuses, including the Swedish Melanoma Register and the Swedish Cancer Registry, for which completeness of information at diagnosis is known to be very high. In the Dutch national cancer registry, all newly diagnosed malignancies are recorded, and it has nationwide coverage since 1989, whereas the Danish cancer registry began systematic data collection in 1943, and registration has been mandated by administrative order since $1987 .{ }^{45}$

The reported stage-specific information, for both survival and recurrence, varies widely in the other non-populationbased studies included in our review (both RCTs and observational studies). Specific studies, which reported survival and recurrence by different sociodemographic, biological, and clinical patient backgrounds identified that survival rates may be substantially affected by these factors. For example, substantial differences in survival are reported by SES. Stage I/II OS ranged from $91.6 \%$ for low SES patients to $97.3 \%-98.3 \%$ for middle/high SES patients. ${ }^{37}$ This is mostly likely due to differences in early detection, as well as treatment patterns and follow-up. ${ }^{19}$ Three studies included OS and DSS estimates according to number of lymph nodes involved in CMM patients, with all studies reporting substantial differences. ${ }^{20,32,33}$ For example, the Dutch registry study and an Italian retrospective study reported approximately half the 5-year OS rate when two or more lymph nodes were involved compared to only one lymph node involved $(27.1 \%$ versus $50.1 \%$ for the Dutch study; $39.6 \%$ versus $81.4 \%$ for the Italian study). ${ }^{20,33}$ This further supports the importance of adequate substaging of stage III CMM patients according to number of involved lymph nodes. Differences were also observed for RFS, for example, by SES (from $81.7 \%$ for low SES patients to $91.8 \%$ for high SES patients). ${ }^{37}$

Stage-specific recurrence-free survival rates were not reported from any of the large registry studies, probably due to a lack of structured follow-up reporting in these settings; consequently, the best sources for the assessment of recurrence risk by stage were RCTs (Table 3), while nine observational studies also reported recurrence-free survival rates (Table 4). As was the case with the reported stagespecific survival data, most of the studies reporting recurrence outcomes had defined inclusion criteria in terms of the CMM stage their patient population sample comprised.

\section{Limitations}

Although the five registry studies ${ }^{18-20,42,43}$ included are assumed to be of higher quality than the small-sized singlecenter studies, in practice, most registries may suffer from various degrees of underreporting. While the Swedish, the Danish, and the Dutch registry studies are nationwide population studies with high coverage of the national population, the German study covered only a section, $40 \%$, of the population. This could mean that regional differences in CMM prevalence and quality of diagnosis and treatment options can influence stage at diagnosis and related survival. Also, the lack of completeness in stage-specific information at recurrence in the registry studies as well as incomplete information on histopathological prognostic factors may influence the reported results. For example, more than 5,000 patients in the Swedish study had unknown stage of disease at diagnosis.

Furthermore, registry studies may not capture follow-up data as accurately as prospective cohort studies or RCTs. Missing information on death, owing to incompleteness of follow-up, may have a disproportionate effect on survival estimates, although linking of registries to national cause of death registries limits this bias. ${ }^{19,20}$ In addition, changes in treatment strategies like sentinel lymph node biopsy and staging classification provides further challenges for the interpretation of the overall data.

The data generated from seven RCTs included in our study may not be representative of survival patterns in the general patient population, because the trial populations are typically highly selective due to strict inclusion and exclusion criteria; however, they also provide data with high quality 
since the follow-up may have been more stringent. Indeed, it may be valuable for potential authors interested in performing a trial with similar inclusion criteria to have the available data from these RCTs listed in our review.

Most of the identified studies had defined inclusion criteria in terms of CMM stage and treatments under review. In effect, this limited the reporting of stage-specific data to subsets of patients for each study. However, when taken together, the studies cover all CMM stages and, hence, provide an overview of the general landscape in Europe in terms of stage-specific survival.

It should also be emphasized that it is challenging to compare data from different timeframes owing to the change in behavior (sun exposure) and awareness over time. Interventions such as $\mathrm{SN}$ procedures have also resulted in a change in staging, with more accurate staging in recent years.

\section{Conclusion}

The studies identified in this review highlight large variations in stage-specific survival and rates of recurrence between European countries. From the 26 included studies, which represented nine countries, stage-specific information for survival and recurrence varied: 5-year OS rates were 95\%-101\% (stage I), 65\%-92.8\% (stage II), 41\%-71\% (stage III), and 9\%-28\% (stage IV); 5-year RFS was reported less frequently: $56 \%$ (stage II) and 28\%-44\% (stage III).

Owing to differing study designs and populations, it is difficult to make detailed comparisons between studies. It is likely that differences in country guidelines and success in early diagnosis of CMM, as well as approaches to treatment contribute to differences in reported outcomes. However, a number of studies included evaluations enabling comparisons in OS and recurrence-free survival estimates by key patient sociodemographic characteristics, which suggest that differences in these factors can result in substantial attenuation or reduction of the survival estimates for separate patient groups. Further large-sample population-based studies are needed to provide a more comprehensive overview of patterns of CMM stage-specific survival within European populations.

Changes in epidemiology may be of relevance for planned future studies in CMM, with new agents likely to enter the adjuvant setting. Recently in Europe, stage migration toward less-advanced CMM at diagnosis and a shift in distribution toward higher proportion of patients with better prognosis have been seen. This can lead to underestimation of required sample size and a delay until clinical trials report outcome. In addition, the degree of heterogeneity in treatment of earlystage CMM in different parts of Europe and its impact on clini- cal outcome is not well characterized. A characterization of stage-specific risk of recurrence and survival in more modern cohorts is thus relevant from a clinical and patient perspective and might also be helpful in the design of clinical trials.

\section{Acknowledgments}

Scientific consultancy on the study was provided by IMS Health, Sweden. This study was funded by Amgen Limited.

\section{Disclosure}

This study was supported by Amgen Limited. Johan Hansson was funded by The Swedish Cancer Society, The Radiumhemmet Research Funds, The Swedish Research Council, and The Stockholm County Council. At the time of writing, Demetris Pillas, Aliki Taylor, and Moninder Kaur were employed by Amgen Limited, and Aliki Taylor owned Amgen stock. Fernanda Costa Svedman has no conflicts of interest. Johan Hansson was acting as a consultant for IMS Health (formerly Pygargus) during the conduct of the study. Johan Hansson has received personal fees from Roche, Bristol-Myers Squibb, Novartis, and Merck, outside the submitted work. Ragnar Linder received a grant from Amgen Ltd to carry out the study to develop a report on survival after CMM in Europe. No grant was given for the manuscript development. Amgen and other pharmaceutical companies are regular clients to Pygargus/IMS Health, outside the submitted work. The authors report no other conflicts of interest in this work.

\section{References}

1. International Agency for Research on Cancer. GLOBOCAN 2012. Estimated Cancer Incidence, Mortality, and Prevalence Worldwide in 2012. Lyon, France: International Agency for Research on Cancer; 2012. Available from: http://globocan.iarc.fr. Accessed November 10, 2014.

2. Erdmann F, Lortet-Tieulent J, Schüz J, et al. International trends in the incidence of malignant melanoma 1953-2008 - are recent generations at higher or lower risk? Int J Cancer. 2013;132(2):385-400.

3. Jemal A, Siegel R, Ward E, et al. Cancer statistics, 2006. CA Cancer J Clin. 2006;56(2):106-130.

4. Forsea AM, Del Marmol V, de Vries E, Bailey EE, Geller AC. Melanoma incidence and mortality in Europe: new estimates, persistent disparities Br J Dermatol. 2012;167(5):1124-1130.

5. Howlader N, Noone AM, Krapcho M, et al. SEER Cancer Statistics Review, 1975-2008. Bethesda, MD: National Cancer Institute, 2011.

6. De Angelis R, Sant M, Coleman MP, et al; EUROCARE-5 Working Group. Cancer survival in Europe 1999-2007 by country and age: results of EUROCARE-5 - a population-based study. Lancet Oncol. 2014; 15:23-34.

7. Berrino F, De Angelis R, Sant M, et al. Survival for eight major cancers and all cancers combined for European adults diagnosed in 1995-1999: results of the EUROCARE-4 study. Lancet Oncol. 2007;8(9):773-783.

8. Sant M, Allemani C, Santaquilani M, et al. EUROCARE-4. Survival of cancer patients diagnosed in 1995-1999. Results and commentary. Eur J Cancer. 2009;45(6):931-991. 
9. Crocetti E, Mallone S, Robsahm TE, et al. Survival of patients with skin melanoma in Europe increases further: results of the EUROCARE-5 study. Eur J Cancer. Epub September 5, 2015.

10. Eggermont AM, Chiarion-Sileni V, Grob JJ, et al. Adjuvant ipilimumab versus placebo after complete resection of high-risk stage III melanoma (EORTC 18071): a randomised, double-blind, phase 3 trial. Lancet. Oncol. 2015;16(5):522-530.

11. Guida M, Pisconti S, Colucci G. Metastatic melanoma: the new era of targeted therapy. Expert Opin Ther Targets. 2012;16(Suppl 2): S61-S70.

12. Schadendorf D, Hodi FS, Robert C, et al. Pooled analysis of longterm survival data from phase II and phase III trials of ipilimumab in unresectable or metastatic melanoma. J Clin Oncol. 2015;33(17): 1889-1894.

13. Chapman PB, Hauschild A, Robert C, et al. Improved survival with vemurafenib in melanoma with BRAF V600E mutation. N Engl J Med. 2011;364(26):2507-2516

14. FDA Approves Second PD-1 Inhibitor, Nivolumab, for Melanoma. Department of Health and Human Services. FDA U.S. Food and Drug Administration. Available from: http://www.cancernetwork.com/ melanoma/fda-approves-second-pd-1-inhibitor-nivolumab-melanoma. Accessed March 16, 2016.

15. Trametinib and Dabrafenib. Department of Health and Human Services. FDA U.S. Food and Drug Administration. Available from: http://www. fda.gov/Drugs/InformationOnDrugs/ApprovedDrugs/ucm381451.htm. Accessed March 16, 2016.

16. Feinstein AR, Sosin DM, Wells CK. The Will Rogers phenomenon. Stage migration and new diagnostic techniques as a source of misleading statistics for survival in cancer. $N$ Engl J Med. 1985;312(25): 1604-1608.

17. Moher D, Liberati A, Tezlaff J, Altman DG; PRISMA Group. Preferred reporting items for systematic reviews and meta-analyses: the PRISMA statement. PLoS Med. 2009;6:e10000097.

18. Eisemann N, Jansen L, Holleczek B, et al. Up-to-date results on survival of patients with melanoma in Germany. Br J Dermatol. 2012;167(3):606-612.

19. Eriksson H, Lyth J, Mansson-Brahme E, et al. Low level of education is associated with later stage at diagnosis and reduced survival in cutaneous malignant melanoma: a nationwide population-based study in Sweden. Eur J Cancer. 2013;49(12):2705-2716.

20. de Waal AC, Aben KK, van Rossum MM, Kiemeney LA. Melanoma of unknown primary origin: a population-based study in the Netherlands. Eur J Cancer. 2013;49(3):676-683.

21. Hancock BW, Wheatley K, Harris S, et al. Adjuvant interferon in highrisk melanoma: the AIM HIGH Study - United Kingdom Coordinating Committee on Cancer Research randomized study of adjuvant low-dose extended-duration interferon Alfa-2a in high-risk resected malignant melanoma. J Clin Oncol. 2004;22(1):53-61.

22. Kleeberg UR, Suciu S, Brocker EB, et al. Final results of the EORTC $18871 / \mathrm{DKG} 80-1$ randomised phase III trial. rIFN- $\alpha 2 \mathrm{~b}$ versus rIFN- $\gamma$ versus ISCADOR $M$ versus observation after surgery in melanoma patients with either high-risk primary (thickness $>3 \mathrm{~mm}$ ) or regional lymph node metastasis. Eur J Cancer. 2004;40(3):390-402.

23. Eggermont AM, Suciu S, MacKie R, et al. Post-surgery adjuvant therapy with intermediate doses of interferon alfa $2 \mathrm{~b}$ versus observation in patients with stage IIb/III melanoma (EORTC 18952): randomised controlled trial. Lancet. 2005;366(9492):1189-1196.

24. Garbe C, Radny P, Linse R, et al. Adjuvant low-dose interferon $\{\alpha\} 2 \mathrm{a}$ with or without dacarbazine compared with surgery alone: a prospectiverandomized phase III DeCOG trial in melanoma patients with regional lymph node metastasis. Ann Oncol. 2008;19(6):1195-1201.

25. Eggermont AM, Suciu S, Testori A, et al. Long-term results of the randomized phase III trial EORTC 18991 of adjuvant therapy with pegylated interferon alfa-2b versus observation in resected stage III melanoma. J Clin Oncol. 2012;30(31):3810-3818.
26. Hansson J, Aamdal S, Bastholt L, et al. Two different durations of adjuvant therapy with intermediate-dose interferon alfa- $2 b$ in patients with high-risk melanoma (Nordic IFN trial): a randomised phase 3 trial. Lancet Oncol. 2011;12(2):144-152.

27. Gillgren P, Drzewiecki KT, Niin M, et al. $2 \mathrm{~cm}$ versus $4 \mathrm{~cm}$ surgical excision margins for primary cutaneous melanoma thicker than $2 \mathrm{~mm}$ : a randomised, multicentre trial. Lancet. 2011;378(9803): $1635-1642$.

28. Koskivuo I, Hernberg M, Vihinen P, et al. Sentinel lymph node biopsy and survival in elderly patients with cutaneous melanoma. Br J Surg. 2011;98(10):1400-1407.

29. Debarbieux S, Duru G, Dalle S, Beatrix O, Balme B, Thomas L. Sentinel lymph node biopsy in melanoma: a micromorphometric study relating to prognosis and completion lymph node dissection. Br J Dermatol. 2007;157(1):58-67.

30. Kunte C, Geimer T, Baumert J, et al. Prognostic factors associated with sentinel lymph node positivity and effect of sentinel status on survival: an analysis of 1,049 patients with cutaneous melanoma. Melanoma Res. 2010;20(4):330-337.

31. Hohnheiser AM, Gefeller O, Gohl J, Schuler G, Hohenberger W, Merkel S. Malignant melanoma of the skin: long-term follow-up and time to first recurrence. World J Surg. 2011;35(3):580-589.

32. Meier A, Satzger I, Volker B, Kapp A, Gutzmer R. Comparison of classification systems in melanoma sentinel lymph nodes - an analysis of 697 patients from a single center. Cancer. 2010;116(13): 3178-3188.

33. Cascinelli N, Bombardieri E, Bufalino R, et al. Sentinel and nonsentinel node status in stage IB and II melanoma patients: twostep prognostic indicators of survival. J Clin Oncol. 2006;24(27): 4464-4471.

34. Mandala M, Imberti GL, Piazzalunga D, et al. Clinical and histopathological risk factors to predict sentinel lymph node positivity, diseasefree and overall survival in clinical stages I-II AJCC skin melanoma: outcome analysis from a single-institution prospectively collected database. Eur J Cancer. 2009;45(14):2537-2345.

35. Testori A, De Salvo GL, Montesco MC, et al. Clinical considerations on sentinel node biopsy in melanoma from an Italian multicentric study on 1,313 patients (SOLISM-IMI). Ann Surg Oncol. 2009;16(7):2018-2027.

36. Quaglino P, Marenco F, Osella-Abate S, et al. Vitiligo is an independent favourable prognostic factor in stage III and IV metastatic melanoma patients: results from a single-institution hospital-based observational cohort study. Ann Oncol. 2010;21(2):409-414.

37. Mandalà M, Imberti GL, Piazzalunga D, et al. Association of socioeconomic status with Breslow thickness and disease-free and overall survival in stage I-II primary cutaneous melanoma. Mayo Clin Proc. 2011;86(2):113-119.

38. Nowecki ZI, Rutkowski P, Nasierowska-Guttmejer A, Ruka W. Survival analysis and clinicopathological factors associated with false-negative sentinel lymph node biopsy findings in patients with cutaneous melanoma. Ann Surg Oncol. 2006;13(12):1655-1663.

39. Rutkowski P, Nowecki ZI, Dziewirski W, et al. Melanoma without a detectable primary site with metastases to lymph nodes. Dermatol Surg. 2010;36(6):868-876.

40. de Vries M, Speijers MJ, Bastiaannet E, et al. Long-term follow-up reveals that ulceration and sentinel lymph node status are the strongest predictors for survival in patients with primary cutaneous melanoma. Eur J Surg Oncol. 2011;37(8):681-687.

41. Kettlewell S, Moyes C, Bray C, et al. Value of sentinel node status as a prognostic factor in melanoma: prospective observational study. $B M J$. 2006;332(7555):1423.

42. Plym A, Ullenhag GJ, Breivald M, Lambe M, Berglund A. Clinical characteristics, management and survival in young adults diagnosed with malignant melanoma: a population-based cohort study. Acta Oncol. 2014;53(5):688-696. 
43. Bay C, Kejs A, Storm H, Engholm, G. Incidence and survival in patients with cutaneous melanoma by morphology, anatomical site and TNM stage: a Danish Populational-based Register Study 1989-2011. Cancer Epidemiol. 2015;39:1-7.

44. de Vries E, Bray FI, Eggermont AM, Coebergh JW; European Network of Cancer Registries. Monitoring stage-specific trends in melanoma incidence across Europe reveals the need for more complete information on diagnostic characteristics. Eur J Cancer Prev. 2004;13(5) $387-395$.
45. Storm HH, Michelsen EV, Clemmensen IH, Pihl J. The Danish Cancer Registry - history, content, quality and use. Dan Med Bull. 1997;44(5):535-539. 


\section{Supplementary materials}

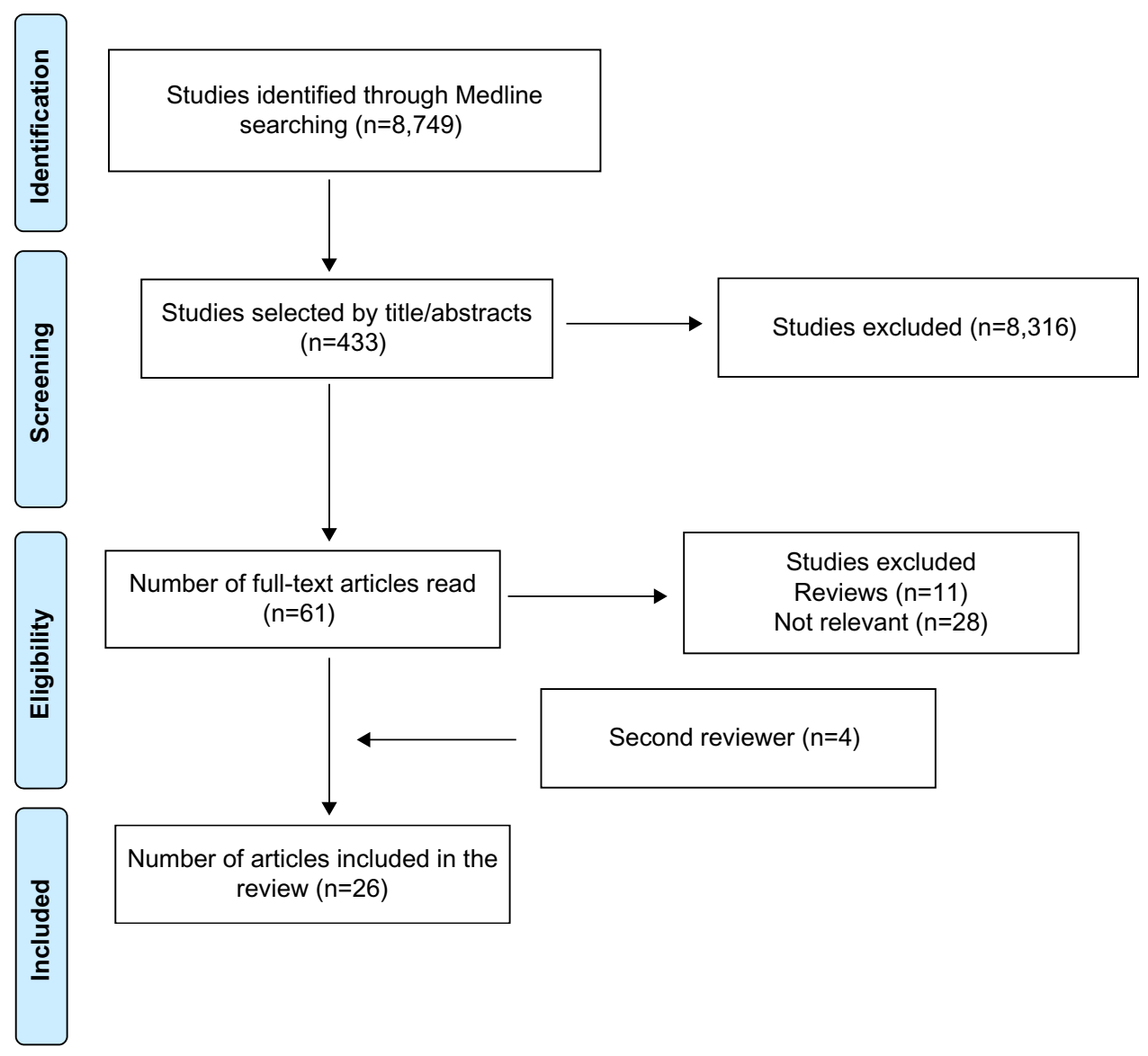

Figure SI Search flow diagram (according to the PRISMA statement).

Abbreviation: PRISMA, Preferred Reporting Items for Systematic Reviews and Meta-Analyses. 
Table SI PRISMA systematic review reporting checklist

\begin{tabular}{llll}
\hline Section/topic & $\#$ & Checklist item & Reported at \\
\hline Title & & Identify the report as a systematic review, meta-analysis, or both. & Title \\
Title & I & Id
\end{tabular}

\section{Abstract}

Structured summary

\section{Introduction}

Rationale

Objectives

\section{Methods}

Protocol and registration

Eligibility criteria

Information sources

Search

Study selection

Data collection process

Data items

Risk of bias in individual studies

Summary measures

Synthesis of results

Risk of bias across studies

Additional analyses

\section{Results}

Study selection

Study characteristics
2

Provide a structured summary including, as applicable: background; objectives; data sources; study eligibility criteria, participants, and interventions; study appraisal and synthesis methods; results; limitations; conclusions and implications of key findings; systematic review registration number.

3 Describe the rationale for the review in the context of what is already known.

Provide an explicit statement of questions being addressed with reference to participants, interventions, comparisons, outcomes, and study design (PICOS).

Indicate if a review protocol exists, if and where it can be accessed (eg, Web address), and, if available, provide registration information including registration number.

6 Specify study characteristics (eg, PICOS, length of follow-up) and report characteristics (eg, years considered, language, and publication status) used as criteria for eligibility, giving rationale. 7 Describe all information sources (eg, databases with dates of coverage, contact with study authors to identify additional studies) in the search and date last searched.

8 Present full electronic search strategy for at least one database, including any limits used, such that it could be repeated.

9 State the process for selecting studies (ie, screening, eligibility, included in systematic review, and, if applicable, included in the meta-analysis).

10 Describe method of data extraction from reports (eg, piloted forms, independently, in duplicate) and any processes for obtaining and confirming data from investigators.

II List and define all variables for which data were sought (eg, PICOS, funding sources) and any assumptions and simplifications made.

12 Describe methods used for assessing risk of bias of individual studies (including specification of whether this was done at the study or outcome level), and how this information is to be used in any data synthesis.

I3 State the principal summary measures (eg, risk ratio, difference in means).

14 Describe the methods of handling data and combining results of studies, if done, including measures of consistency (eg, $\left.l^{2}\right)$ for each meta-analysis.

15 Specify any assessment of risk of bias that may affect the cumulative evidence (eg, publication bias, selective reporting within studies).

I6 Describe methods of additional analyses (eg, sensitivity or subgroup analyses, meta-regression), if done, indicating which were prespecified.

17 Give numbers of studies screened, assessed for eligibility, and included in the review, with reasons for exclusions at each stage, ideally with a flow diagram.

I8 For each study, present characteristics for which data were extracted (eg, study size, PICOS, follow-up period) and provide the citations.
Abstract

Introduction

Introduction

Methods

Methods

Methods, Supplementary material

Supplementary material

Methods

Methods

Methods, Supplementary material

Methods

Methods

N/A

Methods, Discussion

N/A

Supplementary material

Tables I-4 
Table SI (Continued)

\begin{tabular}{|c|c|c|c|}
\hline Section/topic & \# & Checklist item & Reported at \\
\hline Risk of bias within studies & 19 & $\begin{array}{l}\text { Present data on risk of bias of each study and, if available, any } \\
\text { outcome-level assessment (see Item I2) }\end{array}$ & $\mathrm{N} / \mathrm{A}$ \\
\hline Results of individual studies & 20 & $\begin{array}{l}\text { For all outcomes considered (benefits or harms), present, for } \\
\text { each study: I) simple summary data for each intervention group } \\
\text { and } 2 \text { ) effect estimates and confidence intervals, ideally with a } \\
\text { forest plot. }\end{array}$ & Tables 2-4 \\
\hline Synthesis of results & 21 & $\begin{array}{l}\text { Present results of each meta-analysis done, including confidence } \\
\text { intervals and measures of consistency. }\end{array}$ & $\mathrm{N} / \mathrm{A}$ \\
\hline Risk of bias across studies & 22 & $\begin{array}{l}\text { Present results of any assessment of risk of bias across studies } \\
\text { (see Item 15). }\end{array}$ & $\mathrm{N} / \mathrm{A}$ \\
\hline Additional analysis & 23 & $\begin{array}{l}\text { Give results of additional analyses, if done (eg, sensitivity or } \\
\text { subgroup analyses, meta-regression [see Item I6]). }\end{array}$ & $\mathrm{N} / \mathrm{A}$ \\
\hline \multicolumn{4}{|l|}{ Discussion } \\
\hline Summary of evidence & 24 & $\begin{array}{l}\text { Summarize the main findings including the strength of evidence } \\
\text { for each main outcome; consider their relevance to key groups } \\
\text { (eg, health care providers, users, and policy makers). }\end{array}$ & Discussion \\
\hline Limitations & 25 & $\begin{array}{l}\text { Discuss limitations at study and outcome level (eg, risk of bias), } \\
\text { and at review level (eg, incomplete retrieval of identified research, } \\
\text { reporting bias). }\end{array}$ & Discussion \\
\hline Conclusions & 26 & $\begin{array}{l}\text { Provide a general interpretation of the results in the context of } \\
\text { other evidence, and implications for future research. }\end{array}$ & Discussion \\
\hline \multicolumn{4}{|l|}{ Funding } \\
\hline Funding & 27 & $\begin{array}{l}\text { Describe sources of funding for the systematic review and other } \\
\text { support (eg, supply of data); role of funders for the systematic } \\
\text { review. }\end{array}$ & $\begin{array}{l}\text { Acknowledgment of Research } \\
\text { Support/Disclosures/Conflicts } \\
\text { of Interests }\end{array}$ \\
\hline
\end{tabular}

Abbreviations: PRISMA, Preferred Reporting Items for Systematic Reviews and Meta-Analyses; N/A, not applicable.

Table S2 Medline search command

\begin{tabular}{|c|c|}
\hline Key concept/s & Term \\
\hline \multirow[t]{2}{*}{ Melanoma } & (“Melanoma” [Mesh] OR “malignant melanoma” [all fields]) \\
\hline & AND \\
\hline Survival & (“Survival” [Mesh] OR “Mortality” [Mesh] OR “Death” [Mesh] OR “Disease Progression” [Mesh] \\
\hline Recurrence & OR “Recurrence” [Mesh] OR “Neoplasm Metastasis” [Mesh] OR “metasta*” [all fields] OR “General \\
\hline \multirow[t]{2}{*}{ Additional relevant keywords } & Surgery” [Mesh] OR “surgery” [all fields] OR “surgical” [all fields] OR “resection” [all fields]) \\
\hline & NOT \\
\hline \multirow[t]{6}{*}{ Geographical restriction } & (“America” [all fields] OR “American” [all fields] OR “Australia” [all fields] OR “Australian” [all fields] \\
\hline & OR “Canada” [all fields] OR “Canadian” [all fields] OR “Japan” [all fields] OR “Japanese” [all fields] OR \\
\hline & “Brazil” [all fields] OR "Brazilian” [all fields] OR "China” [all fields] OR "Chinese” [all fields] OR "India” \\
\hline & [all fields] OR “New Zealand” [all Fields] OR “Africa” [all fields] OR “African” [all fields] OR “Korea” \\
\hline & [all Fields] OR “Korean” [all fields] OR “Mexico” [all fields] OR “Mexican” [all fields]) \\
\hline & AND \\
\hline \multirow[t]{2}{*}{ Publication date } & (“2004/0I/0I” [PDAT]: “20I5/I2/3I” [PDAT]) \\
\hline & AND \\
\hline Language restriction & English [lang] \\
\hline
\end{tabular}

Notes: Date last search was performed: January 26, 2016.

\section{Publish your work in this journal}

Clinical Epidemiology is an international, peer-reviewed, open access, online journal focusing on disease and drug epidemiology, identification of risk factors and screening procedures to develop optimal preventative initiatives and programs. Specific topics include: diagnosis, prognosis, treatment, screening, prevention, risk factor modification,

Submit your manuscript here: http://www.dovepress.com/clinical-epidemiology-journal

\section{Dovepress}

systematic reviews, risk \& safety of medical interventions, epidemiology \& biostatistical methods, and evaluation of guidelines, translational medicine, health policies \& economic evaluations. The manuscript management system is completely online and includes a very quick and fair peer-review system, which is all easy to use. 